\title{
BMJ Open Seroprevalence of hepatitis B virus infection in Cameroon: a systematic review and meta-analysis
}

\author{
Jean Joel Bigna, ${ }^{1,2}$ Marie A Amougou, ${ }^{3,4}$ Serra Lem Asangbeh, ${ }^{5}$ \\ Angeladine Malaha Kenne, ${ }^{1}$ Steve Raoul N Noumegni, ${ }^{2,6}$ Elodie T Ngo-Malabo,, ${ }^{3,4}$ \\ Jean Jacques Noubiap ${ }^{7}$
}

To cite: Bigna JJ, Amougou MA, Asangbeh SL, et al.

Seroprevalence of hepatitis B virus infection in Cameroon: a systematic review and meta-analysis. BMJ Open 2017;7:e015298. doi:10.1136/ bmjopen-2016-015298

- Prepublication history and additional material for this paper are available online. To view these files please visit the journal online (http://dx.doi. org/10.1136/bmjopen-2016015298).

Received 28 November 2016 Revised 6 May 2017 Accepted 25 May 2017

CrossMark

For numbered affiliations see end of article.

Correspondence to

Dr Jean Joel Bigna; bignarimjj@ yahoo.fr

\section{ABSTRACT}

Objective Better knowledge of hepatitis B virus (HBV) infection prevalence at the national level can help to implement pertinent strategies to address HBV related burden. The aim was to estimate the seroprevalence of HBV infection in Cameroon.

Design Systematic review and meta-analysis.

Participants People residing in Cameroon.

Data sources Electronic databases including PubMed/ MEDLINE, African Journals Online (AJOL), ScienceDirect, WHO-Afro Library, WHO-IRIS, African Index Medicus, National Institute of Statistics and National AIDS Control Committee, Cameroon; regardless of language and from 1 January 2000 to 30 September 2016. This was completed with a manual search of references of relevant papers. Risk of bias in methodology of studies was measured using the Newcastle-Ottawa Scale.

Results Out of 511 retrieved papers, 44 studies with a total of 105603 individuals were finally included. The overall pooled seroprevalence was $11.2 \%$ (95\% Cl 9.7\% to $12.8 \%$ ) with high heterogeneity between studies $\left({ }^{2}=97.9 \%\right)$. Egger's test showed no publication bias $(p=0.167)$. A sensitivity analysis excluding individuals at high risk of HBV infection and after adjustment using trim and fill method showed a pooled seroprevalence of $10.6 \%$ (95\% Cl 8.6\% to 12.6\%) among 100501 individuals (general population, blood donors and pregnant women). Sources of heterogeneity included geographical regions across country and setting (rural $13.3 \%$ vs urban $9.0 \%$ ), and implementation of HBV universal immunisation (born after $9.2 \%$ vs born before $0.7 \%$ ). Sex, site, timing of data collection, HBV screening tools and methodological quality of studies were not sources of heterogeneity.

Limitation Only a third of the studies had low risk of bias in their methodology.

Conclusion The seroprevalence of HBV infection in Cameroon is high. Effective strategies to interrupt the transmission of HBV are urgently required. Specific attention is needed for rural settings, certain regions and people born before the implementation of the HBV universal immunisation programme in Cameroon in 2005. Registration PROSPER0, CRD42016042654.

\section{INTRODUCTION}

Hepatitis B virus (HBV) infection is a global public health problem affecting millions of

\section{Strengths and limitations of this study}

To the best of our knowledge, this is the first systematic review and meta-analysis that focuses on hepatitis B virus (HBV) infection in Cameroon.

- This review included more studies compared with previously published global meta-analysis; in addition, the prevalence for specific populations were estimated; and the difference between sex, geographical regions, HBV screening tools, status regarding implementation of HBV universal immunisation programme and residence areas were assessed.

- Strong methodological and statistical procedures were used.

- Across studies, HBV screening tools and their sensitivity and specificity may be different; this may influence estimates.

people every year and causing disability and death. ${ }^{1}$ Globally, it is estimated that approximatively 257 million people are infected, particularly in low-income and middle-income countries. ${ }^{23}$ About 1 million people die each year $(\sim 2.7 \%$ of all deaths) from causes related to viral hepatitis, mostly liver disease, including liver cancer and cirrhosis. ${ }^{14}$ In highly endemic areas, hepatitis B is most commonly spread from mother to child at birth (perinatal transmission), or through horizontal transmission (exposure to infected blood), especially from an infected child to an uninfected child during the first 5 years of life. ${ }^{25}$ An estimated $50 \%$ to $80 \%$ of cases of primary liver cancer result from infection with HBV. ${ }^{6}$ In sub-Saharan Africa, infections by HBV affect between 5\% and $10 \%$ of the population. In many countries, HBV infection is the leading cause of liver transplants. The economic load of the disease is also important; in the terminal stage, treatments are expensive, the cost easily reaching hundreds of thousands of dollars per person. ${ }^{7}$

Following a global summit in 2015, WHO launched the global programme against 
hepatitis with the following goals, by 2030 , to reduce by $90 \%$ the number of new cases of hepatitis $\mathrm{B}$, reduce by $65 \%$ the number of hepatitis B-related deaths and treat $80 \%$ of eligible people infected with hepatitis B. ${ }^{8}$ The systematic review and meta-analysis published in Lancet by Schweitzer and colleagues in 2015 provides the global prevalence of HBV with estimate by countries. ${ }^{9}$ However, details on the source of data for each country are not provided, and the review gives an overall estimate of the prevalence, without emphasis on specific populations, especially at-risk groups to which interventions should be mostly directed. Therefore, the purpose of our review is to provide a detailed summarisation of the data on the prevalence of HBV in the general Cameroonian population, and specific populations such as blood donors, pregnant women and healthcare workers in particular. We strongly believe such detailed data are more likely to influence decision-making towards intervention to curb the burden of HBV in Cameroon.

\section{OBJECTIVE}

To conduct a systematic review and meta-analysis of data in populations residing within Cameroon as reported in studies published to determine the prevalence of $\mathrm{HBV}$ infection.

\section{METHODS}

This review was reported following the PRISMA guidelines. ${ }^{10}$ The preferred reporting items for systematic reviews and meta-analyses checklist can be found in online supplementary file $\mathrm{S} 1$. This review was registered in PROSPERO International prospective register of systematic reviews, registration number CRD42016042654. Centre for Reviews and Dissemination guidelines were used as reference for the methodology of this review. ${ }^{11}$

\section{Setting}

Cameroon is a Central African country situated slightly above the equator. It covers a surface area of $472650 \mathrm{~km}^{2}$ divided into 10 administrative regions: Littoral, Far-North, North, Adamawa, North-West, South-West, West, East, South and Centre where the capital city (Yaoundé) is located. Cameroon counted 22.25 million inhabitants in 2013. ${ }^{12}$ The HBV universal immunisation programme was introduced in Cameroon in 2005. In Cameroon, for children born in 2005 or later, HBV vaccination is free of charge throughout the expanded programme on immunisation. In this vaccine programme, children receive three $\mathrm{HBV}$ vaccine doses at 6 weeks, 10 weeks and 14 weeks of life. Beside this programme, the vaccine is not free of charge for the general population and was not free of charge for children born before 2005. The circulation of three $\mathrm{HBV}$ genotypes $\mathrm{A}, \mathrm{E}$ and $\mathrm{D}$ was reported in patients in Cameroon, however, genotypes $\mathrm{A}$ and $\mathrm{E}$ are predominantly found. ${ }^{13-15}$
Criteria for considering studies for the review

\section{Inclusion criteria}

- We considered cross-sectional, case-control or cohort studies of participants residing in Cameroon reporting the prevalence of $\mathrm{HBV}$ infection, or enough data to compute this estimate.

- HBV infection diagnosed based on the presence of hepatitis B surface antigen.

\section{Exclusion criteria}

- Studies conducted among Cameroonian populations residing outside Cameroon.

- Studies not performed in humans.

- Studies in subgroups of participants selected on the basis of the presence of any other viral hepatitis.

- Case series, reviews, commentaries and editorials.

- Studies lacking primary data and/or explicit method description.

- Duplicates (for studies published in more than one report, the most comprehensive and up-to-date version was used).

\section{Search strategy used to identify relevant studies}

The search strategy was implemented in two stages:

- We performed a comprehensive search of databases to identify all relevant articles published on $\mathrm{HBV}$ infection in Cameroon from 1 January 2000 to 31 September 2016 without language restriction. A systematic search of PubMed/MEDLINE, African Journals Online, Science Direct, WHO Afro Library, WHO Institutional Repository for Information Sharing, African Index Medicus, National Institute of Statistics, Cameroon (http://www.statistics-cameroon. org/), National AIDS Control Committee, Cameroon (http://www.cnls.cm/), and Health Sciences and Diseases (the biomedical journal of the Faculty of Medicine and Biomedical Sciences, University of Yaoundé 1, Cameroon) was undertaken using a predefined strategy based on the combination of relevant terms. We used both text words and medical subject heading terms; for example, 'viral hepatitis B', 'hepatitis virus B', 'HBV' and 'Cameroon'. These terms and their variants were used in varying combinations. The literature search strategy was adapted to suit each database. The main search strategy conducted in PubMed/MEDLINE is shown in online supplementary file S2. The last search was conducted on 17 October 2016.

- We manually searched the reference lists of eligible articles and relevant reviews.

\section{Selection of included studies}

Two investigators independently identified articles and sequentially screened their titles and abstracts for eligibility. Full texts of articles deemed potentially eligible were acquired. These investigators further independently assessed the full text of each study for eligibility, and 
consensually retained studies to be included. Disagreement was solved by a third investigator and discussion among authors. We used a screening guide to ensure that the selection criteria were reliably applied by all assessors.

\section{Appraisal of the quality of included studies}

An adapted version of the Newcastle-Ottawa Scale (NOS) was used to evaluate the methodological quality of studies included in this review. ${ }^{16}$ This scale was also used to assess the risk of bias affecting study findings. The NOS is formulated by a star allocation system, assigning a maximum of nine stars for the risk of bias in three areas: selection of study groups, comparability of groups and ascertainment of the outcome of interest. There is no validation study that provides a cut-off score for rating low-quality studies; a priori, we arbitrarily established that zero to three stars, four to six stars and seven to nine stars would be considered at high, moderate and low risk of bias, respectively.

\section{Data extraction and management}

One investigator extracted data regarding general information (authors, year, regions in Cameroon, type of publication), study characteristics (study design, setting, sample size, mean or median age, age range, proportions of male participants, diagnosis criteria for hepatitis B, disease specific/profile specific to the study population) and prevalence of hepatitis B. We considered two main groups of populations regarding their a priori risk to HBV infection: low-risk population (general population, blood donors and pregnant women) and high-risk population (HIV-infected people, haemodialysis patients, patients with sickle cell disease, patients with hepatocellular carcinoma, and healthcare workers). Where only primary data (sample size and number of cases) were available, these were used to calculate the prevalence estimate. Where prevalence rates or relevant data for estimating them were not available, we contacted the corresponding author of the study to request the missing information. In the absence of response or no availability of full data, the corresponding study was excluded. A second investigator double-checked extracted data for accuracy.

\section{Data synthesis including assessment of heterogeneity}

Using meta-analysis, prevalence data were summarised by specific populations. Standard errors for the study-specific estimates were determined from the point estimate and the appropriate denominators, assuming a binominal distribution. We pooled the study-specific estimates using a random-effects meta-analysis model to obtain an overall summary estimate of the crude prevalence across studies, after stabilising the variance of individual studies with the use of the Freeman-Tukey double arcsine transformation. ${ }^{17}$ A sensitive analysis was conducted excluding populations at high risk of HBV infection: healthcare workers, HIV-infected people, patients with hepatocellular carcinoma and patients with sickle cell disease. Heterogeneity was assessed using the $\chi^{2}$ test on Cochran's $Q$ statistic ${ }^{18}$ and quantified by calculating the $I^{2} \cdot{ }^{19}$ Values of $25 \%, 50 \%$ and $75 \%$ for $I^{2}$ represent, respectively, low, medium and high heterogeneity. Where substantial heterogeneity was detected, when possible, we performed subgroup analysis to investigate the possible sources of heterogeneity using the following grouping variables: sex, study setting, study site, geographical region in Cameroon, status regarding implementation of the HBV universal immunisation in Cameroon, HBV screening tools and study methodological quality. Only populations at low risk of $\mathrm{HBV}$ infection were considered for these subgroup analyses. We assessed the presence of publication bias using funnel plots and the formal Egger's test. ${ }^{20} \mathrm{~A} p$ value $<0.10$ was considered indicative of statistically significant publication bias. In addition, we conducted a trim and fill adjusted analysis to remove the most extreme small studies from the positive side of the funnel plot, re-computing the effect size at each iteration, until the funnel plot is symmetrical about the (new) effect size. ${ }^{21}$ We assessed inter-rater agreement for study inclusion using Cohen's $\kappa$ coefficient. ${ }^{22}$ Data were analysed using the statistical software STATA V.13.0 for Windows (Stata, 2013; Stata Statistical Software: Release 13; College Station, Texas, USA).

\section{RESULTS}

\section{Study selection}

Initially, a total of 511 articles were identified. After elimination of duplicates, screening titles and abstracts, 460 papers were found irrelevant and excluded. Agreement between investigators on abstract selection was high $(\kappa=0.88, \mathrm{p}<0.001)$. Full texts of the remaining 47 papers were scrutinised for eligibility, among which 9 were excluded (figure 1) ${ }^{23-30}$ Overall, 38 papers including 44 studies were found eligible; hence they were included in the meta-analysis.

\section{Characteristics of included studies}

The characteristics of each included study are presented in online supplementary file S3. The 38 included papers were published from 2001 to 2016 and included studies conducted from 1994 to 2015 in the 10 regions of Cameroon. ${ }^{13}$ 31-67 Twelve studies were conducted among blood donors, ${ }^{33} 3536404548-5056596610$ among pregnant women, ${ }^{13} 313234353739444748586061648$ among HIV-infected people, ${ }^{46} 48676$ in the general population, ${ }^{415155576365} 4$ among healthcare workers, ${ }^{42} 4854621$ among haemodialysis patients, ${ }^{43} 1$ in patients with hepatocellular carcinoma, ${ }^{55} 1$ for HIV-infected pregnant women $^{44}$ and 1 in patients with sickle cell disease. ${ }^{53}$ The age of included subjects varied from 1 year to 82 years. Three studies were population-based, ${ }^{41} 515739$ were hospital-based $^{13}$ 31-40 42-50 52-56 58-64 6667 and 2 studies did not report the setting. ${ }^{6065}$ Eight studies were conducted solely in rural areas, ${ }^{13} 4148586722$ in urban areas only, ${ }^{33} 364043444647495052-5762-6466$ and 14 in both urban and rural. ${ }^{31} 3235373842515259-6165$ One study included only men, ${ }^{57} 11$ only women ${ }^{13} 31323435373944485258$ and 32 both sexes. ${ }^{33} 3638$ 40-43 45-47 49-51 53-56 59-68 Concerning 


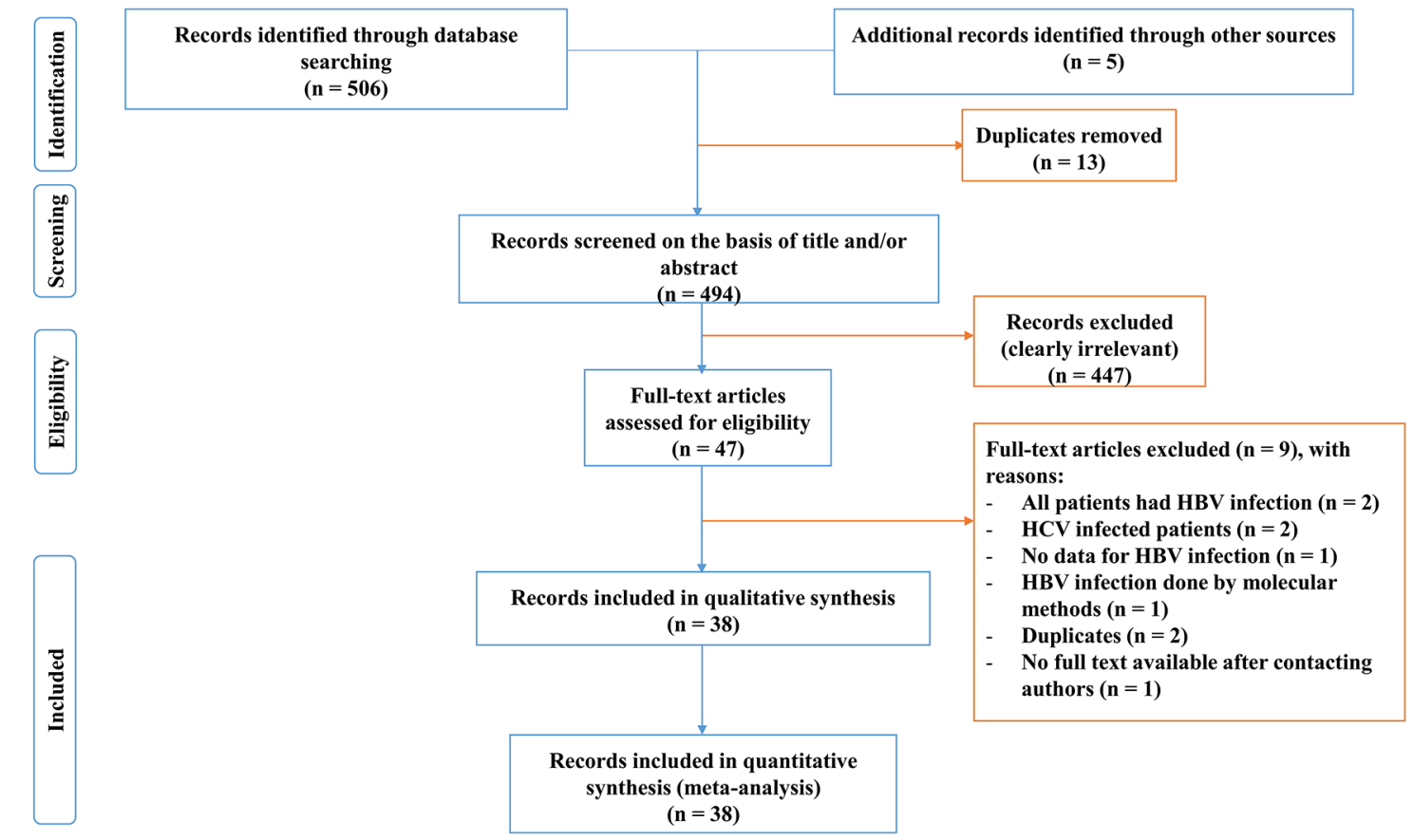

Figure 1 Process of identification and selection of studies for inclusion in the review. HBV, hepatitis B virus; HCV, hepatitis C virus.

diagnostic test used in studies, 22 were a rapid diagnostic test, 13 32-36 $38404548495354565859616265-67$ 9 were an enzyme linked immunoassay test, ${ }^{37} 41-4447525764$ 5were enzyme immunoassay test, ${ }^{31} 394660631$ was a chemiluminescent microparticle immunoassay and 7 studies not described in detail diagnostic tests. ${ }^{40} 45505155$

\section{Methodological quality of studies}

Fifteen (32.6\%) studies had low, ${ }^{33} 343740414445525356-596719$ $(41.3 \%)$ moderate 1331323536394243464950545560626566 and 10 $(26.1 \%)^{38474851616364}$ high risk of bias in their methodological quality. One paper was case control, ${ }^{55} 10$ studies were analysis of retrospective data 3338404547596067 and 33 studies were cross-sectional studies ${ }^{13} 31$ 32 34-37 39 41-44 46 48-54 56-5861-66 (see online supplementary file S3).

\section{Overall pooled prevalence of HBV infection}

There was a wide variation in $\mathrm{HBV}$ infection prevalence (figure 2). The crude overall prevalence of HBV infection in the pooled sample of 105601 individuals was $11.2 \%$ (95\% CI $9.7 \%$ to $12.8 \%$ ). The sensitive overall pooled prevalence was also $9.5 \%$ (95\% CI $7.9 \%$ to $11.4 \%$ ) in a pooled sample of 100501 individuals at low risk of HBV infection (figure 3). As expected, the prevalence of HBV infection (17.3, 95\% CI 12.2 to 23.1) was higher in a population at high risk of $\mathrm{HBV}$ infection ( $p$-difference $=0.008$ ) (figure 4 ). The heterogeneity between studies were high in both crude $\left(I^{2}=98.0 \%\right.$, p-heterogeneity $\left.<0.001\right)$ and sensitive $\left(I^{2}=98.6 \%\right.$, p-heterogeneity $\left.<0.001\right)$ meta-analyses. For the overall crude prevalence, funnel plot suggested publication bias (see online supplementary file S4) but the results of Egger's regression test did not confirm any publication bias $(\mathrm{p}=0.167)$. For the sensitive overall prevalence, funnel plot suggested publication bias (see online supplementary file S5) confirmed by the results of Egger's regression test $(p=0.017)$. The adjusted sensitive HBV infection prevalence on trim and fill method was $10.6 \%$ (95\% CI $8.6 \%$ to $12.6 \%$ ).

\section{Source of heterogeneity and subgroup analysis}

Table 1 presents the HBV prevalence of all subgroups including assessment of heterogeneity, assessment of publication bias and assessment of difference between subgroups. Source of heterogeneity included regions in Cameroon ( $p$-difference <0.001), settings ( $p$-difference $=0.001)$ and status regarding implementation of the HBV universal immunisation ( $p$-difference $<0.001)$. Results from meta-analysis suggested that the prevalence of $\mathrm{HBV}$ infection is higher in the North region and rural settings and lower in the West region and urban settings. The prevalence of $\mathrm{HBV}$ infection was also higher in people whose samples were collected before implementation of the HBV universal immunisation programme. There was no difference on pooled prevalence between subgroups of the population at low risk of HBV infection (general population, blood donors and pregnant women) ( $p$-difference $=0.567)$. Also, sex, study sites, timing of data collection, HBV screening tools and methodical quality of studies were not sources of heterogeneity ( $p$-difference $>0.05$ ). The publication bias was found for all group analyses except for sex and HBV screening tools.

\section{DISCUSSION}

We investigated the prevalence of $\mathrm{HBV}$ infection in different populations in Cameroon. The information 


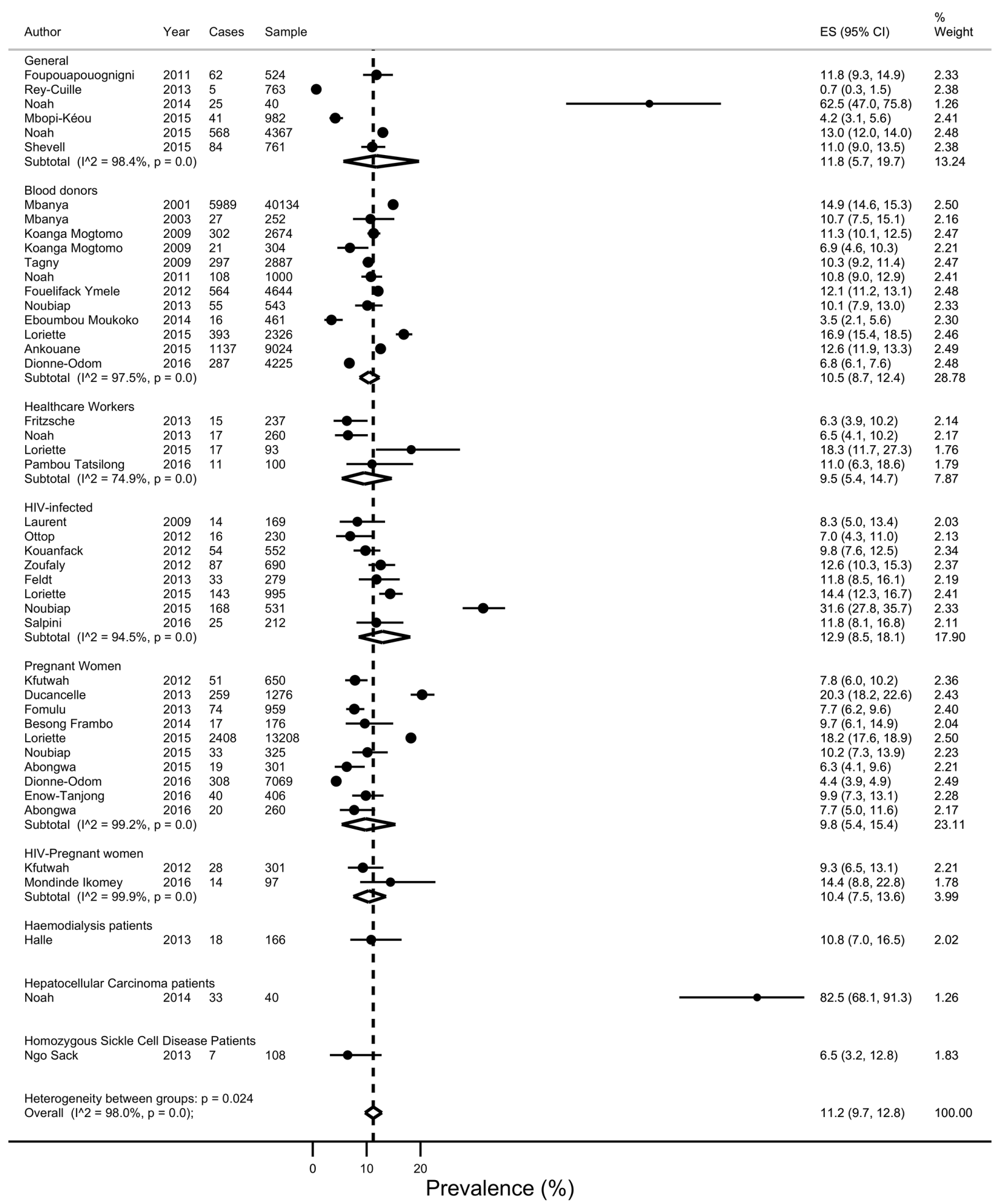

Figure 2 Forest plot of the prevalence of hepatitis B virus infection in all subpopulations in Cameroon.

provided by this systematic review and meta-analysis may contribute to improve knowledge on HBV infection epidemiology in Cameroon and in sub-Saharan Africa, as well as inform national policy makers. It is important to note that only a third of the 44 studies included in this review had low risk of bias in their methodological quality. Therefore, the results should be interpreted with caution due to the presence of studies with poor methodological quality. However, as shown in the subgroup analysis, methodological quality did not influence HBV seroprevalence.

We found a pooled prevalence of $11.2 \%$ (95\% CI 9.7\% to $12.8 \%$ ) close to that found in the sensitive analysis excluding high-risk participants, $10.6 \%$ (95\% CI $8.6 \%$ to 


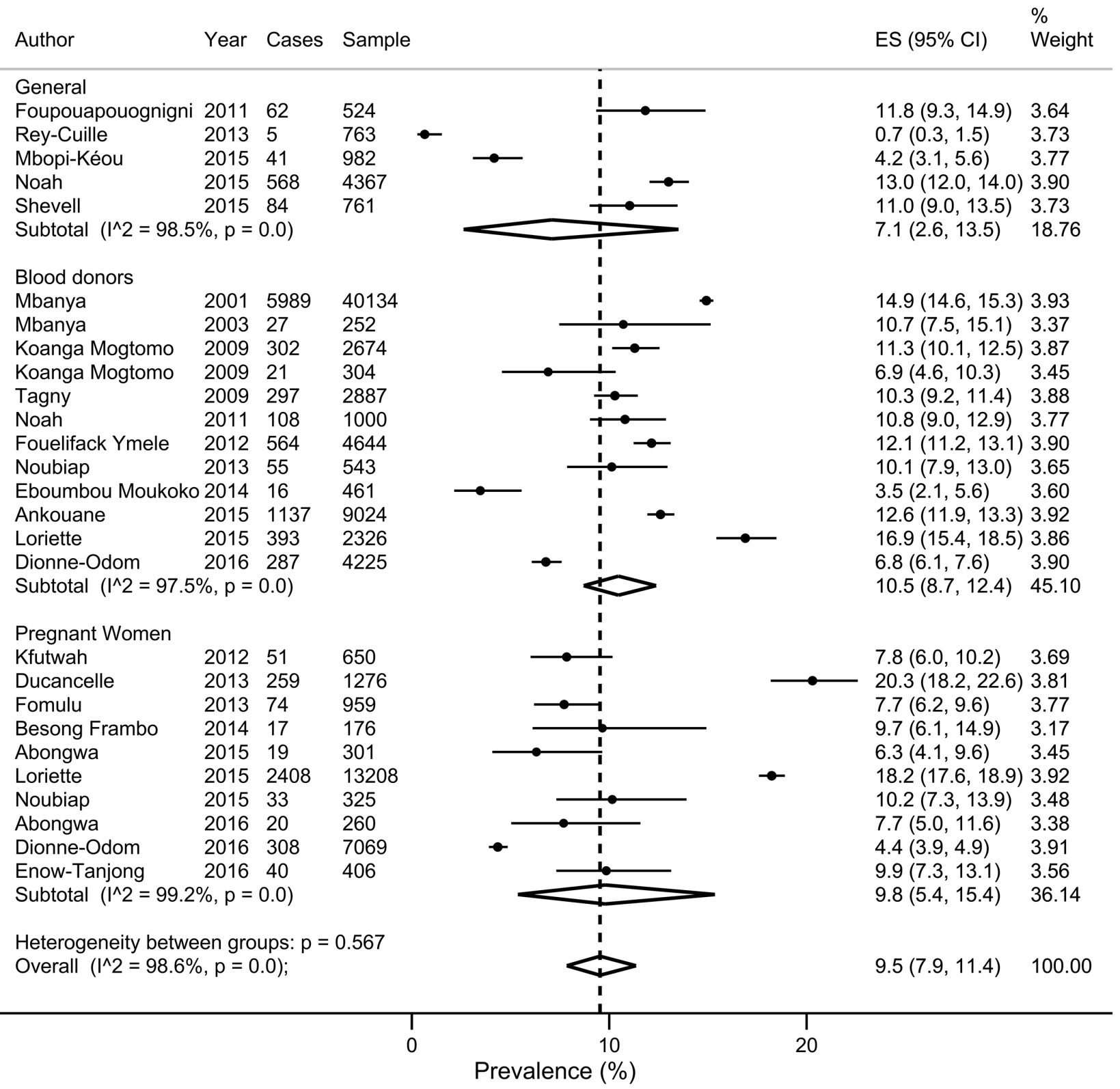

Figure 3 Forest plot of the prevalence of hepatitis B virus infection in subpopulations at low risk in Cameroon.

$12.6 \%)$. According to $\mathrm{WHO}$, these prevalence rates are high $(\geq 8 \%){ }^{3}$ This sensitive prevalence is slightly lower than the prevalence found in a global systematic review (12.2\%; $95 \%$ CI $11.7 \%$ to $12.8 \%$ ) published in 2013 which included 17 studies from pregnant women, blood donors, healthcare workers and general populations from Cameroon and is higher than the reported prevalence in Africa $(8.8 \%) .{ }^{9}$ Our meta-analysis, in addition included 31 studies from 2013 to 2016. Despite the high heterogeneity between studies, there was difference between population groups for prevalence of HBV infection when excluding high-risk individuals. This sensitive analysis suggests that prevalence was homogeneous across groups: around $10 \%$ ( $7.1 \%$ to $10.5 \%)$ and therefore when implementing preventive strategies focusing on the reduction of this prevalence, all groups should benefit from close strategies. The prevalence reported in this study suggests that in a population of 22.25 million inhabitants like in Cameroon, ${ }^{12}$ there are about 2250000 inhabitants infected by HBV. Therefore, access to screening for HBV and treatment should urgently be scaled up nationwide.

Analyses suggest that the prevalence is not influenced by sex distribution, methodological quality of studies, timing of data collection, HBV screening tools and study site. Surprisingly, the prevalence of HBV infection is higher in rural areas compared with urban areas. This discrepancy should be investigated in future studies. Analyses also suggest differences across regions in Cameroon for HBV seroprevalence. We can categorise prevalence across regions in three groups: regions with high ( $>15 \%$; Far-North, North and South regions), with medium (8\%-15\%; Centre, East and South-West) and 


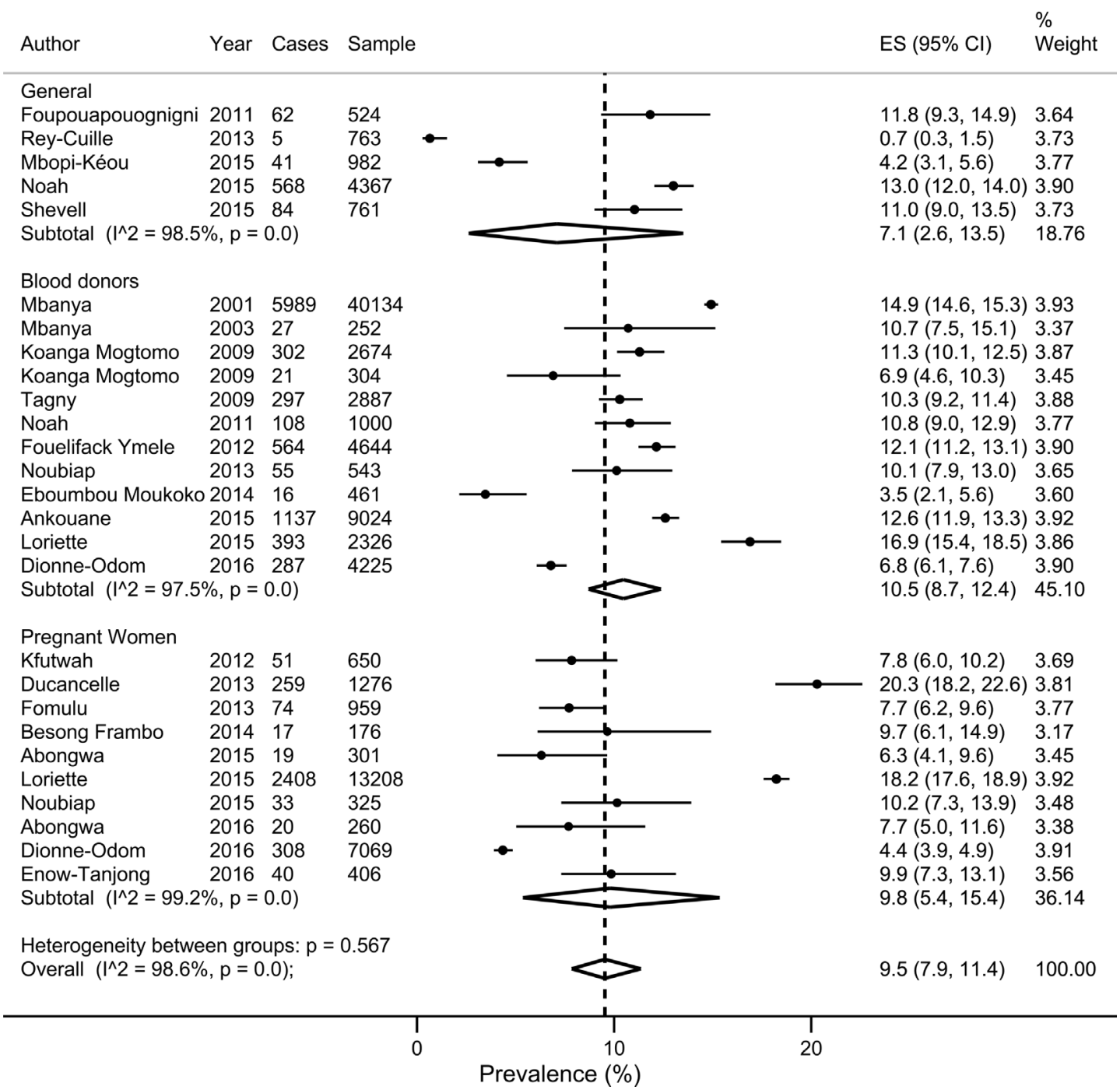

Figure 4 Forest plot of the prevalence of hepatitis B virus infection in Cameroon by risk status.

low HBV seroprevalence ( $<8 \%$, Littoral, North-West and West). Nevertheless, this result requires a cautious interpretation since certain regions in the analysis included only one study (West, North and East). Specific strategies should be implemented for rural settings and certain regions (East, Far North and South) with high prevalence. One can note that the Adamawa Region was not represented. Data also suggest that the implementation of HBV universal immunisation had good impact of HBV prevalence. This result should be interpreted with caution, only one study represented the people in which samples were collected after this implementation; and lacking data on the main HBV transmission route in the country is questionable for the interpretation. Studies are needed to estimate the main route of HBV transmission.

To the best of our knowledge, this is the first systematic review and meta-analysis that focuses on HBV infection in Cameroon. We included more studies compared with previously published meta-analysis; ${ }^{9}$ in addition, the prevalence for specific populations was estimated; and the difference between sex, geographical regions, HBV screening tools, status regarding implementation of
HBV universal immunisation programme and residence areas were assessed. Strong and reliable methodological and statistical procedures were used. Nevertheless, only a large representative national epidemiological study conducted at the same time in all regions and all specific groups can give a more reliable and accurate overall prevalence of HBV infection. This was done in one study but limited to young men (18-23 years). ${ }^{57}$ In addition, the review included only one study specific to children. Across studies, HBV screening tools and their sensitivity and specificity may be different; this may influence estimates.

\section{CONCLUSION}

Despite the fact that only a third of the studies presented low risk of bias in their methodology, the prevalence of HBV infection in Cameroon is high, both, in the general population and in specific subpopulations. These findings indicate the need of comprehensive and effective strategies to interrupt the transmission of HBV infection in the Cameroonian population. Specific attention is needed for 


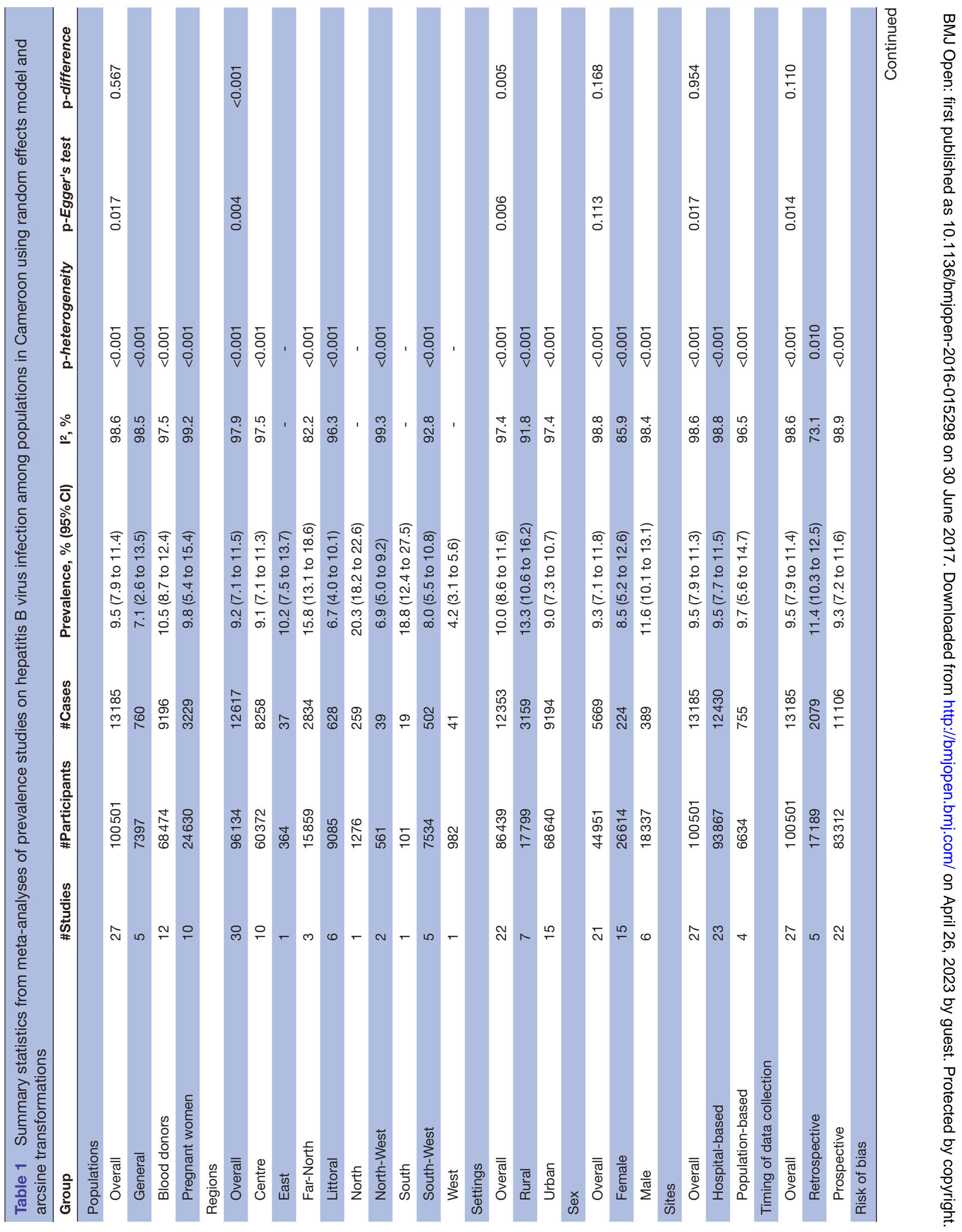




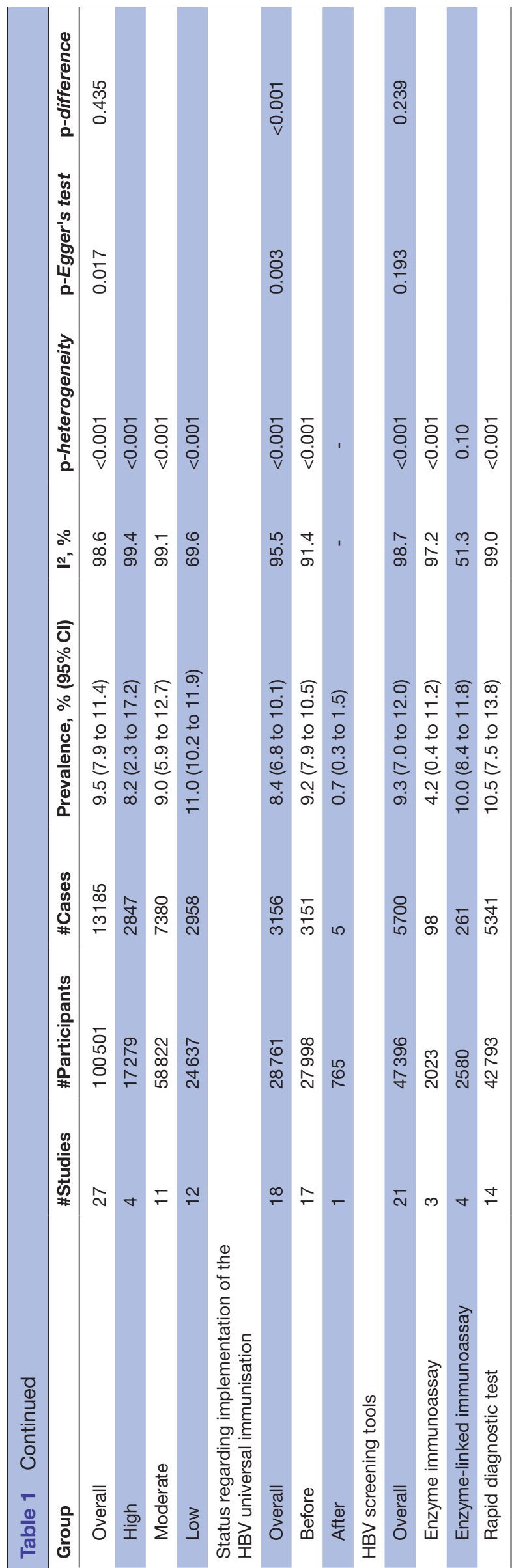

rural settings and certain regions of the country. Health policies makers and stakeholders should facilitate access to HBV immunisation to people born before 2005 .

Author affiliations

${ }^{1}$ Department of Epidemiology and Public Health, Centre Pasteur of Cameroon, Yaound Ã $\odot$, Cameroon

${ }^{2}$ School of Public Health, Faculty of Medicine, University of Paris Sud XI, Le Kremlin BicÃatre, France

${ }^{3}$ Department of Virology, Centre Pasteur of Cameroon, YaoundÃ $\odot$, Cameroon ${ }^{4}$ Faculty of Sciences, University of Yaound $\tilde{A} \odot 1$, YaoundÃ $\odot$, Cameroon

${ }^{5}$ Agence Nationale de Recherche sur le SIDA et les HÃ@patites Virales (ANRS), YaoundÃ@, Cameroon

${ }^{6}$ Faculty of Medicine and Biomedical Sciences,University of YaoundÃ@ 1, Yaound Ã@, Cameroon

${ }^{7}$ Department of Medicine, Groote Schuur Hospital and University of Cape Town, Cape Town, South Africa

Contributors Conception and design: JJB; Search strategy: JJB. Study selection: JJB, JJN. Data extraction: JJB, ETN-M, MAA, JJN. Data analysis: JJB. Manuscript drafting: JJB, SLA. Manuscript revision: JJB, SLA, AMK, SRNN, ETN-M, MAA, JJN; Guarantor of the review: JJB. Approved the final version of the manuscript: All authors.

Funding This research received no specific grant from any funding agency in the public, commercial or not-for-profit sectors.

Competing interests None declared.

Provenance and peer review Not commissioned; externally peer reviewed.

Data sharing statement № additional data are available.

Open Access This is an Open Access article distributed in accordance with the Creative Commons Attribution Non Commercial (CC BY-NC 4.0) license, which permits others to distribute, remix, adapt, build upon this work non-commercially, and license their derivative works on different terms, provided the original work is properly cited and the use is non-commercial. See: http://creativecommons.org/ licenses/by-nc/4.0/

(c) Article author(s) (or their employer(s) unless otherwise stated in the text of the article) 2017. All rights reserved. No commercial use is permitted unless otherwise expressly granted.

\section{REFERENCES}

1. World Health Organization. Prévention et lutte contre I'hépatite virale: cadre pour l'action mondiale. 2012. http://www.who.int/csr/disease/ hepatitis/GHP Framework Fr.pdf

2. World Health Organization. Hepatitis B: Fact sheet. 2017. http:// www.who.int/mediacentre/factsheets/fs204/en/index.html

3. World Health Organization. Guidelines for the prevention, care and treatment of persons with chronic hepatitis B infection. 2015 . http:// apps.who.int/iris/bitstream/10665/154590/1/9789241549059_eng. pdf

4. WHO Executive Board. Viral hepatitis. 2009. http://apps.who.int/gb/ ebwha/pdf files/EB126/B126 15-en.pdf

5. World Health Organization. Hepatitis B: fact Sheet. 2016. http://www. who.int/mediacentre/factsheets/fs204/en/

6. Perz JF Armstrong GL, Farrington LA et al. The contributions of hepatitis $B$ virus and hepatitis $C$ virus infections to cirrhosis and primary liver cancer worldwide. J Hepatol 2006;45:529-38.

7. El Khoury AC, Wallace C, Klimack WK, et al. Economic burden of hepatitis C-associated diseases: Europe, Asia Pacific, and the Americas. J Med Econ 2012;15:887-96.

8. World Health Organization. Health topics: hepatitis. 2016. http:// www.who.int/topics/hepatitis/en/

9. Schweitzer A, Horn J, Mikolajczyk RT, et al. Estimations of worldwide prevalence of chronic hepatitis B virus infection: a systematic review of data published between 1965 and 2013. Lancet 2015;386:1546-55

10. Moher D, Liberati A, Tetzlaff J, et al. Preferred reporting items for systematic reviews and meta-analyses: the PRISMA statement. PLoS Med 2009;6:e1000097.

11. Centers for Reviews and Dissemination. CRD's guidance for undertaking reviews in healthcare: Centers for Reviews and Dissemination, 2009. 
12. Cameroon's National Institue of Statistics. Generalities on Cameroon. secondary generalities on Cameroon, 2016. http://www.statisticscameroon.org/manager.php?id=11

13. Ducancelle A, Abgueguen P, Birguel J, et al. High endemicity and low molecular diversity of hepatitis B virus infections in pregnant women in a rural district of North Cameroon. PLoS One 2013;8:e80346.

14. Kurbanov F, Tanaka Y, Fujiwara K, et al. A new subtype (subgenotype) Ac (A3) of hepatitis $B$ virus and recombination between genotypes $A$ and $\mathrm{E}$ in Cameroon. J Gen Virol 2005;86:2047-56.

15. Kramvis A, Kew MC. Epidemiology of hepatitis B virus in Africa, its genotypes and clinical associations of genotypes. Hepatol Res 2007;37:S9-S19.

16. Wells GA, Shea B, O'Connell D, et al. The Newcastle-Ottawa Scale (NOS) for assessing the quality of nonrandomised studies in metaanalyses. 2014. http://www.ohri.ca/programs/clinical_epidemiology/ oxford.asp

17. Barendregt JJ, Doi SA, Lee YY, et al. Meta-analysis of prevalence. $J$ Epidemiol Community Health 2013;67:974-8.

18. Cochran WG. The combination of estimates from different experiments. Biometrics 1954;10:101-29.

19. Higgins JP, Thompson SG. Quantifying heterogeneity in a metaanalysis. Stat Med 2002;21:1539-58.

20. Egger M, Davey Smith G, Schneider M, et al. Bias in meta-analysis detected by a simple, graphical test. BMJ 1997;315:629-34.

21. Duval S, Tweedie R. Trim and fill: a simple funnel-plot-based method of testing and adjusting for publication Bias in meta-analysis. Biometrics 2000;56:455-63.

22. Viera AJ, Garrett JM. Understanding interobserver agreement: the kappa statistic. Fam Med 2005;37:360-3.

23. Ankouane Andoulo F, Kowo M, Talla P, et al. Epidemiology of Hepatitis B-Associated Hepatocellular Carcinoma in Cameroon. Health Sci Dis 2013;14:16-19.

24. Njouom R, Pasquier C, Ayouba A, et al. Low risk of mother-to-child transmission of hepatitis $C$ virus in Yaounde, Cameroon: the ANRS 1262 study. Am J Trop Med Hyg 2005;73:460-6.

25. Mbougua JB, Laurent C, Kouanfack C, et al. Hepatotoxicity and effectiveness of a Nevirapine-based antiretroviral therapy in HIVinfected patients with or without viral hepatitis $B$ or $C$ infection in Cameroon. BMC Public Health 2010;10:105.

26. Gaynes BN, Pence BW, Atashili J, et al. Prevalence and predictors of Major depression in HIV-infected patients on antiretroviral therapy in Bamenda, a semi-urban center in Cameroon. PLoS One 2012;7:e41699.

27. Luma HN, Eloumou SA, Malongue A, et al. Characteristics of antihepatitis $C$ virus antibody-positive patients in a hospital setting in Douala, Cameroon. Int J Infect Dis 2016;45:53-8.

28. Tufon KA, Meriki HD, Anong DN, et al. Genetic diversity, viraemic and aminotransferases levels in chronic infected hepatitis $B$ patients from Cameroon. BMC Res Notes 2016;9:117.

29. Birguel J, Ndong JG, Akhavan S, et al. [Viral markers of hepatitis B, $C$ and $D$ and $H B$ vaccination status of a health care team in a rural district of Cameroon]. Med Trop 2011;71:201-2.

30. Forbi JC, Ben-Ayed Y, Xia GL, et al. Disparate distribution of hepatitis $B$ virus genotypes in four sub-Saharan african countries. J Clin Virol 2013;58:59-66.

31. Abongwa LE, Clara AM, Edouard NA, et al. Sero-Prevalence of human immunodeficiency virus (HIV) and Hepatitis B virus (HBV) Co-Infection among pregnant women residing in Bamenda Health District, Cameroon. Int J Curr Microbiol App Sci 2015;4:473-83.

32. Abongwa LE, Kenneth P. Assessing prevalence and risk factors of hepatitis $B$ surface antigen amongst pregnant women attending antenatal clinic in the Northwest Region of Cameroon. European Journal of Research in Medical Sciences 2016;4:32-43.

33. Ankouane F, Noah Noah D, Atangana MM, et al. Seroprevalence of hepatitis $B$ and $C$ viruses, HIV-1/2 and syphilis among blood donors in the Yaoundé Central Hospital in the centre region of Cameroon. Transfus Clin Biol 2016;23:72-7.

34. Frambo AA, Atashili J, Fon PN, et al. Prevalence of HBsAg and knowledge about hepatitis $B$ in pregnancy in the Buea Health District, Cameroon: a cross-sectional study. BMC Res Notes 2014;7:394.

35. Dionne-Odom J, Mbah R, Rembert NJ, et al. Hepatitis B, HIV, and Syphilis Seroprevalence in Pregnant Women and Blood Donors in Cameroon. Infect Dis Obstet Gynecol 2016;2016:1-8.

36. Eboumbou Moukoko CE, Ngo Sack F, Essangui Same EG, et al. HIV, HBV, HCV and T. pallidum infections among blood donors and Transfusion-related complications among recipients at the Laquintinie hospital in Douala, Cameroon. BMC Hematol 2014;14:5

37. Enow Tanjong R, Teyim P, Kamga HL, et al. Sero-prevalence of human immunodeficiency virus and hepatitis viruses and their correlation with CD4 T-cell lymphocyte counts in pregnant women in the Buea Health District of Cameroon. IJBCS 2016;10:219-31.

38. Feldt T, Sarfo FS, Zoufaly A, et al. Hepatitis E virus infections in HIV-infected patients in Ghana and Cameroon. J Clin Virol 2013;58:18-23.

39. Fomulu NJ, Morfaw FL, Torimiro JN, et al. Prevalence, correlates and pattern of Hepatitis B among antenatal clinic attenders in YaoundeCameroon: is perinatal transmission of HBV neglected in Cameroon? BMC Pregnancy Childbirth 2013;13:158.

40. Fouelifack Ymele F, Keugoung B, Fouedjio JH, et al. High rates of Hepatitis $\mathrm{B}$ and $\mathrm{C}$ and HIV infections among blood donors in Cameroon: a Proposed Blood Screening Algorithm for Blood Donors in Resource-Limited Settings. J Blood Transfus 2012;2012:1-7.

41. Foupouapouognigni $\mathrm{Y}, \mathrm{Mba} \mathrm{SA}$, Betsem à Betsem $\mathrm{E}$, et al. Hepatitis $B$ and $C$ virus infections in the three Pygmy groups in Cameroon. $J$ Clin Microbiol 2011;49:737-40.

42. Fritzsche C, Becker F, Hemmer CJ, et al. Hepatitis B and C: neglected diseases among health care workers in Cameroon. Trans $R$ Soc Trop Med Hyg 2013;107:158-64.

43. Halle MP, Luma NH, Temfack E, et al. Prevalence of Hepatitis B surface antigen and AntiHIV antibodies among patients on Maintenance Haemodialysis in Douala - Cameroon. Health Diseases and Sciences 2013;14:1-5.

44. Kfutwah AK, Tejiokem MC, Njouom R. A low proportion of HBeAg among HBsAg-positive pregnant women with known HIV status could suggest low perinatal transmission of HBV in Cameroon. Virol J 2012;9:62.

45. Mogtomo ML, Fomekong SL, Kuate HF, et al. [Screening of infectious microorganisms in blood banks in Douala (1995-2004)]. Sante 2009;19:3-8.

46. Kouanfack C, Aghokeng AF, Mondain AM, et al. Lamivudine-resistant HBV infection in HIV-positive patients receiving antiretroviral therapy in a public routine clinic in Cameroon. Antivir Ther 2012;17:321-6.

47. Laurent $\mathrm{C}$, Bourgeois $\mathrm{A}$, Mpoudi-Ngolé $\mathrm{E}$, et al. High rates of active hepatitis $B$ and $C$ co-infections in HIV-1 infected cameroonian adults initiating antiretroviral therapy. HIV Med 2010;11:85-9.

48. Loriette M, Birguel J, Damza R, et al. [An experience of hepatitis $\mathrm{B}$ control in a rural area in Far North Cameroon]. Med Sante Trop 2015;25:422-7.

49. Mbanya DN, Takam D, Ndumbe PM. Serological findings amongst first-time blood donors in Yaoundé, Cameroon: is safe donation a reality or a myth? Transfus Med 2003;13:267-73.

50. Mbanya D, Binam F, Kaptue L. Transfusion outcome in a resourcelimited setting of Cameroon: a five-year evaluation. Int $\mathrm{J}$ Infect Dis 2001;5:70-3.

51. Mbopi-Keou FX, Nkala IV, Kalla GC, et al. [Prevalence and factors associated with HIV and viral hepatitis B and C in the city of Bafoussam in Cameroon]. Pan Afr Med J 2015;20:156.

52. Mondinde Ikomey G, Jacobs GB, Tanjong B, et al. Evidence of Co and triple infections of Hepatitis $B$ and $C$ amongst HIV infected pregnant women in Buea, Cameroon. Health Sci Dis 2016;17.

53. Sack FN, Noah Noah D, Zouhaïratou $\mathrm{H}$, et al. [Prevalence of HBsAg and anti-HCV antibodies in homozygous sickle cell patients at Yaounde Central Hospital]. Pan Afr Med J 2013;14:40.

54. Noah DN, Ngaba GP, Bagnaka SF, et al. [Evaluation of vaccination status against hepatitis $\mathrm{B}$ and $\mathrm{HBsAg}$ carriage among medical and paramedical staff of the Yaoundé Central Hospital, Cameroon]. Pan Afr Med J 2013;16:111.

55. Noah DN, Nko'ayissi G, Ankouane FA, et al. Présentation clinique, biologique et facteurs de Risque Du Carcinome hépatocellulaire: une étude Cas-Témoins à Yaoundé Au Cameroun. Revue de Médecine et de Pharmacie 2014:4

56. Noah Noah D, Njouom R, Bonny Aim?, et al. HBs antigene prevalence in blood donors and the risk of transfusion of hepatitis $\mathrm{b}$ at the central hospital of Yaounde, Cameroon. Open Journal of Gastroenterology 2011;01:23-7.

57. Noah DN, Andoulo FA, Essoh BVM, et al. Prevalence of HBs antigen, and HCV and HIV antibodies in a young male Population in Cameroon. Open Journal of Gastroenterology 2015;05:185-90.

58. Noubiap JJ, Nansseu JR, Ndoula ST, et al. Prevalence, infectivity and correlates of hepatitis B virus infection among pregnant women in a rural district of the Far North Region of Cameroon. BMC Public Health 2015:15:454.

59. Noubiap JJ, Joko WY, Nansseu JR, et al. Sero-epidemiology of human immunodeficiency virus, hepatitis $B$ and $C$ viruses, and syphilis infections among first-time blood donors in Edéa, Cameroon Int J Infect Dis 2013;17:e832-e837.

60. Noubiap JJ, Aka PV, Nanfack AJ, et al. Hepatitis B and C CoInfections in some HIV-Positive populations in Cameroon, West Central Africa: analysis of Samples Collected over more than a decade. PLoS One 2015;10:e0137375. 
61. Ottop FM, Atashili J, Ndumbe PM. Impact of antiretroviral therapy on glycemia and transaminase levels in patients living with HIVIAIDS in Limbe, Cameroon. J Int Assoc Provid AIDS Care 2013;12:23-7.

62. Tatsilong HO, Noubiap JJ, Nansseu JR, et al. Hepatitis B infection awareness, vaccine perceptions and uptake, and serological profile of a group of health care workers in Yaoundé, Cameroon. BMC Public Health 2016;15:706.

63. Rey-Cuille MA, Njouom R, Bekondi C, et al. Hepatitis B virus exposure during childhood in Cameroon, Central African Republic and Senegal after the integration of HBV vaccine in the expanded program on immunization. Pediatr Infect Dis J 2013;32:1110-5.

64. Salpini R, Fokam J, Ceccarelli L, et al. High burden of HBV-Infection and atypical HBV strains among HIV-infected Cameroonians. Curr HIV Res 2016;14:165-71.
65. Shevell L, Meriki HD, Cho-Ngwa F, et al. Epidemiology of human immunodeficiency virus-1 and hepatitis B virus co-infection and risk factors for acquiring these infections in the Fako division of Southwest Cameroon. BMC Public Health 2015;15:1066.

66. Tagny CT, Diarra A, Yahaya R, et al. Characteristics of blood donors and donated blood in sub-Saharan Francophone Africa. Transfusion 2009;49:1592-9.

67. Zoufaly A, Onyoh EF, Tih PM, et al. High prevalence of hepatitis B and syphilis co-infections among HIV patients initiating antiretroviral therapy in the north-west region of Cameroon. Int J STD AIDS 2012;23:435-8

68. Zoufaly A, Fillekes $Q$, Hammerl R, et al. Prevalence and determinants of virological failure in HIV-infected children on antiretroviral therapy in rural Cameroon: a cross-sectional study. Antivir Ther 2013;18:681-90. 